\title{
MEMORANDUM
}

$\delta$
$y$
$\dot{x}$
$\dot{x}$
$\frac{8}{2}$

OPTIMAL CONTROL ALLEVIATION OF TILTING

PROPROTOR GUST RESPONSE

Wayne Johnson

Ames Research Center

and

U.S. Army Air Mobility R\&D Labontory

Moffett Field, Calif. 94035

(HASA-TH-X-62494) CPIIMAL CONTROL

N76-10995

ALIEVIATION OF TILTING PRUPROTOR GUST

RESPONSE (NASA) $27 \mathrm{p} \mathrm{HC} \$ 4.0^{\prime}$ ) CSCL $01 \mathrm{E}$

$\begin{array}{ll}\text { Unclas } \\ 03 / 01 & 01858\end{array}$

October 1975

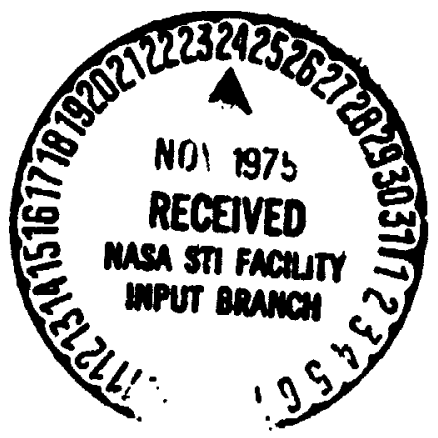




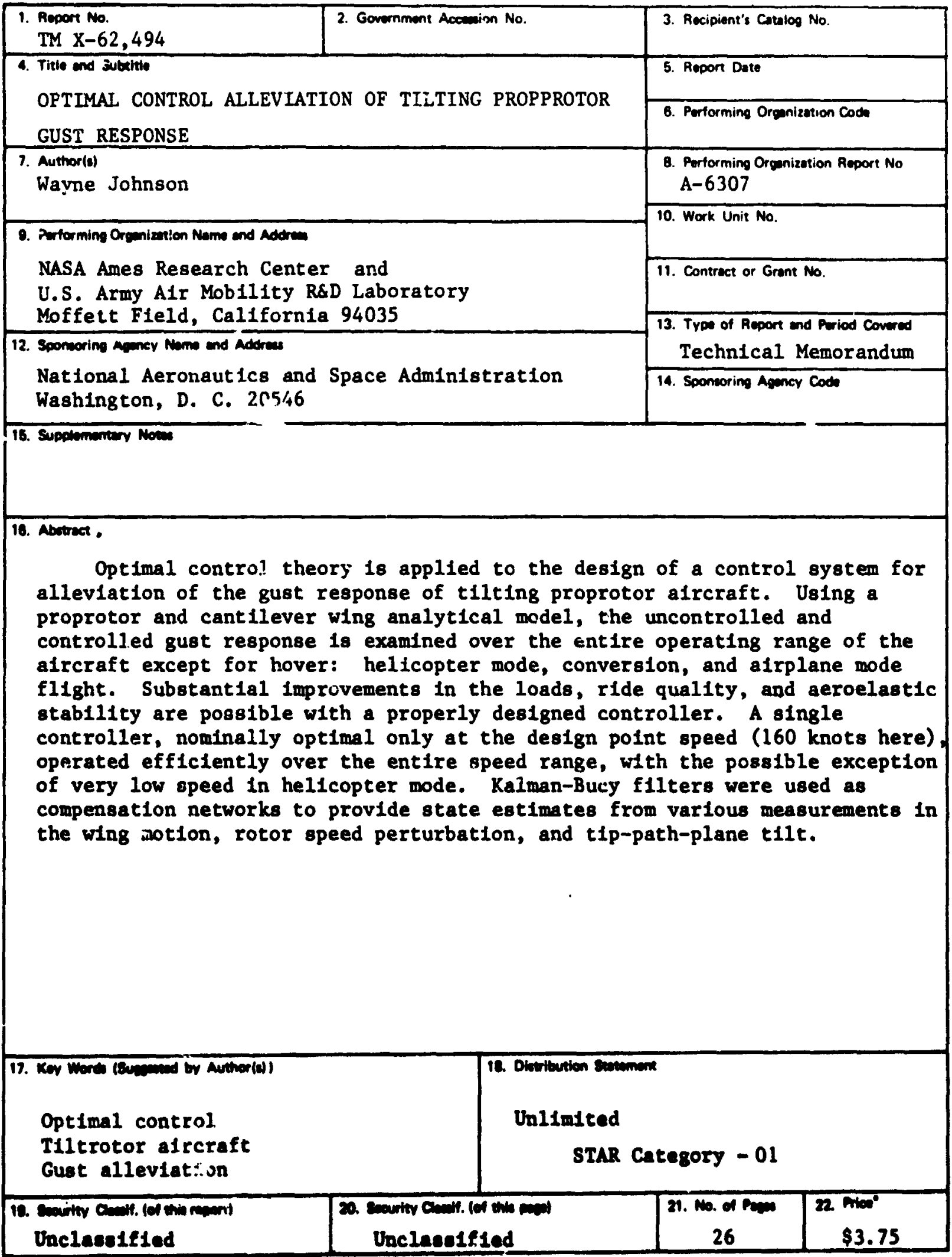

"For ale by the National Technied Information Earvien, Soringfield, Virginie 22161 


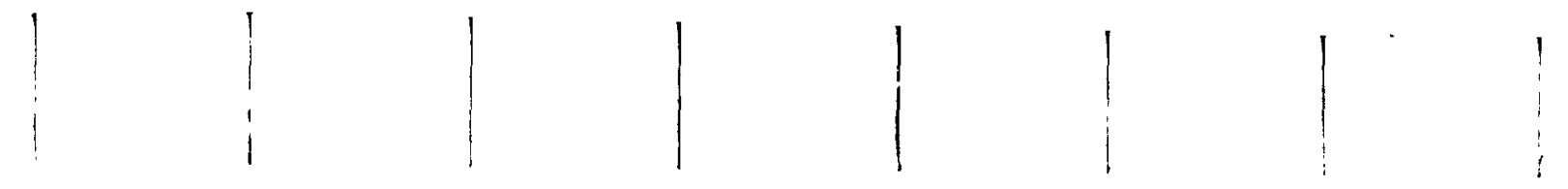

\title{
CONTROL SYSTEM DESIGN
}

\author{
Optimal Controller
}

Optimal control theory will be used to design a gust alleviation system. The theory constructs a feedback controller for a linear system, to minimize a quadratic performance index (ref. 7). Consider a 1inear, time-invarianf system (i.e., the proprotor and wing). Let $x$ be the vector of the system states (degrees of freedom), $u$ the vector of controls, and 8 the vector of gust components. The system is described by a set of constant coefficient, IInear differential equations:

$$
\dot{\mathrm{x}}=\mathrm{Fx}+\mathrm{Gu}+\mathrm{Dg}_{\mathrm{g}}
$$

where F, G, and $D$ are constant matrices. Define the quadratic performance Index as follows:

$$
J=\int_{0}^{\infty}\left(x^{T} A x+u^{T} B u\right) d t
$$

where $A$ is a constant, symetric, and nonnegative definite matrix; and $B$ is constant, symetric, positive definite. Only the case where $A$ and $B$ are also diagonal is considered. The control problem is to find a control law for $u$ to minimize the performance index for arbitrary excitation of the system by the gust disturbance. The solution 18 the optimal deterministic controller (ref. 7), which 18 linear state varlable feedback, $u=-C x$, where $C=B^{-1} G$ Ts, and $S$ is the constant, symetric, positive definite matrix solution of the Ricatti equation

$$
S F+F^{T} S-S G B-1 G^{T} S+A=0
$$

The Rlcatt 1 equation 18 solved by Potter's methos (ref. 8).

The diagonal elements of the welghting matrices $A$ and $B$ may be Interpreted as $\left(x_{\max }\right)^{-2}$ and $\left(u_{\max }\right)^{-2}$ respectively (ref. 6). Only the relative magnitudes of the weights in the performance Index are Important, ince any cowmon factor afmply scales J. Based on the solution for a first order eystem, we may 1nterpret $(A / B) 1 / 2$ as the "galn" of the oystem, which determines the level of the feedback control. No weight 18 placed in $A$ on those otates corresponding to the velocities of the degrees of freedom; it is sufficient to constrain the dieplacement (adding a conetralnt on the velocities may be done wth a ingle additlonal parameter, representing the frequency content of the allowble motlon). In oumary, $A$ and $B$ are diagonal, with no constraint in $A$ on the velocities of degrees of freedon. The remining elewents of the weighting matrices are chosen so the rms acceleration of the wing and rotor wotion have about the sam percent reduction at high gain. For the 8 imballed rotor, weight of $0.1 \mathrm{rad}^{-2}$ was used for the rotor flap, $1 \mathrm{eg}$, and $\psi_{\mathrm{g}}$ degrees of frecdon; a wetght of 1.0 for the rotor coning and the wing degree of freedom; and a walght of $(8 a 1 n)^{-2}$ for the controls (B). For nost of tha results presented here a gain of 10 was ueed. 


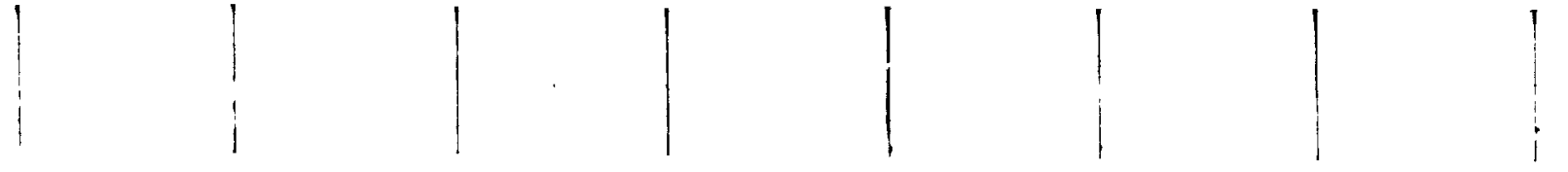

State Estimation

To design a compensation network we consider a Ka1man-Bucy filter to estimate the states from various measurements. The control problem is as defined above, except that we no longer assume perfect knowledge of the system states for the feedback law. Now a limited number of noisy measurements are considered. Let $z$ be the vector of the measurements, $z=H x+v$, where $H$ is a constant matrix; and $v$ is stationary, white, Gaussian measurement noise, with zero mean and a covariance $E\left[v(t) v^{T}(\tau)\right]=R \delta(t-\tau)$. R is a constant, symmetric, positive definite correlation matrix. The control problem is to find the control law for $u$ which minimizes the expected value of the parformance Index for a system with measurement and process nolse. The process noise in this case is the aerodynamic gust disturbance (discussed below). The solution is the optimal controller together with the sta.es estimated by a Kalman-Bucy filter (ref. 6). Thus we have linear feedback, $u=-C x_{e}$, where $C$ is the same matrix as the optimal deterministic controller above, and $x_{e}$ is the estimate of the state which must be obtained from the measurements z. The Kalman-Bucy filter gives a maximum likelthood/minimum variance estimate of the state:

$$
\dot{x}_{e}=F x_{e}+G u-K\left(z-H x_{e}\right)
$$

where $K=-\mathrm{PH}^{\mathrm{T}_{\mathrm{R}}}-1$ and $\mathrm{P}$ is the solution of the matrix Ricatti equation

$$
F P+P F^{T}-P H^{T} R^{-1} H P+D Q D^{T}=0
$$

$Q$ is the correlation matrix of the process nolse (the gust). For the measurement noise, it is assumed that $R$ is diagcnal with elements equal to $\left(10^{6} \Omega\right)^{-1} \mathrm{sec}$; this corresponds to broadband nolse with say a level of $.07 \mathrm{deg}$ rms and a $3 /$ rev break frequency.

\section{Gust Model}

The Kalman-Bucy filter assumes white process nolse. The aerodynamic gust 1s not well represented by a constant spectrum however, rather the gust strength 18 concentrated at low frequencles. A Markov-process gust model is used to obtain the appropriate gust spectrum (ref. 9). The vector of the three gust components is g; let

$$
\dot{8}=-\frac{1}{\tau_{G}} g+w
$$

where $\tau_{G}$ is the correlation time of the gust; and $w$ is stationary, white, Gauselan nolse w1th zero mean and e correlation $E[w(t) w(\tau)]=Q_{\delta} \delta(t-\tau)$. $Q_{G}$ is a constant, symetric, non-nogative definite matrix. It 18 asoumed that $Q_{G} 10$ diagonal, with all elements equal to $2 \sigma \xi_{G} / \tau_{G}$.

Hence the gust velocity 1s a Karkov procese. The three components are uncorrelated, w1th 1dentical etat1at1cs. Eech component of $B$ has gero man and a covariance $E\left(g^{2}\right)=(1 / 2) Q_{G} \tau_{G}=\sigma_{G}^{2}$. So $\sigma_{G}$ is the tere level of the guet 
RESULTS AND DISCUSSION

\author{
Operating State
}

\begin{abstract}
Figure 1 shows the operating states considered for the gimballed profrotor: the schedule of rotor tip speed ( $/ R)$, pylor angle $\left(\alpha_{p}\right)$, and thrust coefficlent-solidity ratio $\left(C_{T} / \sigma\right)$ as a function of flight speed. The resulting advance ratio $\mu$ (the component of forward velocity parallel to the disk plane, divided by the tip speed), and inflow ratio $\lambda$ (normal velocity component divided by tip speed) are also shown. The entire range of tilting proprotor operation is covered, from 0 to 280 knots at sea level standard conditions. Helicopter forward filight extends up to $80 \mathrm{knots}$. The pylon is converted from vertical to horizontal for $V=80$ to 140 knots. Then in airplane mode, $V=140$ to 160 knots, the wing flaps are raised and the rotor speed reduced. Finally alrplane mode cruise extends to 280 knots. Th1s conversion path corresponds roughly to the center of the conversion corridor of a representative tilting proprotor aircraft. Additional detalls of the operating state, and a discussion of the open loop dynamics, are given in reference 6 .
\end{abstract}

\title{
Proprotor Gust Response
}

Figure 2 shows the gust response of the proprotor and wing over the speed range from 40 to 280 knots. We silall first examine the uncontrolled response. The rms rotor flap response is a maximum in high opeed cruise, reaching about $.45 \mathrm{deg} / \mathrm{m} / \mathrm{sec}$. Th1s compares well with calculations for the complete alrcraft, which give .3 to $.5 \mathrm{deg} / \mathrm{m} / \mathrm{sec}$ for $V=200$ to $260 \mathrm{knots}$ (ref. 2). The rms gust strength $1 \mathrm{~s}$ typically $6 \mathrm{~m} / \mathrm{sec}$ in thunderstorms, and $2 \mathrm{~m} / \mathrm{sec}$ in clear air turbulence (CAT). Thus the 30 flap response in CAT 18 of the order $2.6^{\circ}$. The flap response 18 not a loads problem for a gimballed rotor (unless the gimbal stops are encountered), but the large rotor flapping 18 involved in the excitation of the rest of the system. The rms rotor lag response increases greatly with speed, to about $.26 \mathrm{deg} / \mathrm{m} / \mathrm{sec}$ here. This cyclic lag motion produces blade loods for the gimballed rotor, the response at high speed cruise corresponding to the rotor design limit loads typically (ref. 1).

The wing tip vertical acceleration increases greatly with opeed, to about $.4 \mathrm{~g} / \mathrm{m} / \mathrm{sec}$. This compares with about $.2 \mathrm{~g} / \mathrm{m} / \mathrm{sec}$ calculated for the vertical acceleration at the crew station due to vertical gusts with a complete aircraft model (ref. 2). The trend with speed 1s similar for the cantilever wing and complete alrcraft calculations, with a gust alleviation factor of about 2 for the crew station acceleration compared with the wind tip acceleration (note however that the former was calculated for a $3000 \mathrm{~m}$ altitude, and a gust correlation length of $\mathrm{L}-300 \mathrm{~m}$ ). Figure 2 gives a 30 wing tip vest:ical acceleration in CAT of 2.48 at maximum epeed, which is very high. The wing tip chordwise acceleration is low in helicopter mode, increaces in convereion (due to the response to rotor thrust perturbations), and 1s roughly constant in alrplane mode. Figure 2 gives about $.12 \mathrm{~g} / \mathrm{m} / \mathrm{aec}$, compared to about $.07 \mathrm{~g} / \mathrm{m} / \mathrm{acc}$ for the crew station longltudinal acceleration reaponse to longltudinal guste with a complete alrcraft model (ref. 2). The 30 wing tip chordwise acceleration in CAT 1s then of the order $.7 \mathrm{~g}$. 
Optimal Deterministic Controller

Figure 2 compares the gust response for the proprotor and wing uncontrolled and with the optimal deterministic controller. The control system accomplishes a substantial reduction in the gust response. At maximum speed the closed loop flap and lag response is about $5 \%$ of the open lonp response, and the wing tip acceleration is reduced to about $10 \%$ of the open loop level. The 30 flap response in CAT is of the order $0.1^{\circ}$, and the wing tip vertical acceleration $0.3 \mathrm{~g}$. Note that the gust response of the controlled system is relatively independent of speed, in contrast to the large increases with $V$ for the loop response. Figure 2 also shows the damping ratio of the wing vertical bending mode. The wing modes are an important factor in the proprotor gust response. Their natural frequencies are fairly high compared to the gust frequencles, but the resonant response is high because of the very low damping (ref. 14). Hence the control system greatly increases the wing mode dynamic stability in order to reduce the gust response.

The wing flaperon control motion required increases roughly linearly with speed, as the flaperon aerodynamic effectiveness increases, to about $.18 \mathrm{deg} /$ $\mathrm{m} / \mathrm{sec}$ at maximum speed. The rotor collective pitch control required is around .2 to $.3 \mathrm{deg} / \mathrm{m} / \mathrm{sec}$ over the entire speed range. The cyclic control increases with speed in helicopter and conversion modes, and is nearly constant in airplane mode at about $.22 \mathrm{deg} / \mathrm{m} / \mathrm{sec}$. Thus the 30 flaperon and rotor control required in CAT is of the order of $1.2^{\circ}$, which is a reasonable level.

The implementation of the optimal controiler would require that the feedback gains be programmed with the proprotor operating state, since a different control system is designed for each condition. It is preferable to use a single controller over the entire operating range. There are large changes in the open loop dynamics however, due to the variations of the flight speed, rotor speed, and especially pylon angle; hence it is not necessarily expected that a single controller will be feasible. Figure 2 also shows the closed loop gust response using a single controller designed for optimal response at 160 knots. It is observed that nearly the same performance is achleved with this single controller as $w^{\prime}$ :h the optimal controller for each speed - even In conversion mode where the pylon angle 1s changing. There is some degradation in the performance at low opeed in hellcopter mode however; for example, the wing chordwise bending mode damping (not shown) is actually reduced at 40 knots. We are not designing a controller for hover and very low speed anyway of course. If necessary the controller could probably be programed with the pylon angle without too wuch difficulty.

The controllex designed by this process 1o not simple. The otate var1able feedbeck matrix $\mathrm{C}$ hes 84 elemente (18 states, 3 gust components, and 4 controls). While many of the elemente are negligibly small, the reasining feedback loope comprise a fairly sophloticated aystem. For example, for the 160 knot controller the anjor loops are: $\psi_{0}, \psi_{\text {. }}$, rotor coning, wing wotion and wing velocity feedback to rotor collective; rotor flap and lag not1on, flap and lag velocity, wing motion and wing velocity feedback to rotor cyclic; and wing vertical bending veloctty feedback to wing flaperon. There are two particularly notable loops. The wing flaperon control is alwost ontirely 


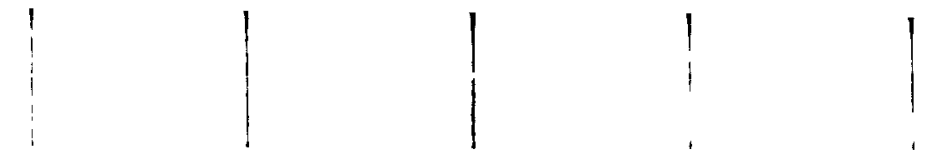

when the wing motion is not considered in the design (f1g. 3). Such a dynamic stability degradation is not acceptable. Such behavior of a control system designed considering the rotor alone has been observed in full-scale tests of a proprotor and a cantilever wing (ref. 15). Figure 5 (from ref. 15) shows the performance obtained with integral feedback of the longltudinal flapping to longitudinal cyclic $\left(\dot{\theta}_{1 s}=-K B_{1 c}\right)$. A substantial reduction of the transient flapping is acileved, but at the expense of increased wing vertical bending motion (the transient motion was obtained by step cyclic ccntrol inpurs). With integral feedback, the steady state flap response was zero, and increasing the gain improved the transient flap dynamics (with reduced flap damping however). The increased wing response for the uncompensated network was unacceptable however, and the wing vertical bending mode damping (not shown) was decreased also, with an unstable polnt at a gain of 5 for 265 knotu. Lagged position feedback of the rotor flapping was also tried. This 10op was somewhat more effective than the integral network in reducing the transient flapping, but produced more wing response; there was wiso a reduction in stability with gain. With a combination of integral and lagged position feedback, a reduction in transtent flapping of about $30 \%$ was achleved with only a small damping reduction and increase in wing motion (combinations were also found with worse performance).

Alternatively, we may examine the control system design with only the wing motion considered. Figure 4 shows the rotor flapping response as a function of gain for an optlmal controller designed with performance index welghts on the wing motion only (and no flaperon control again). The resulting controller has virtually no feedback of the rotor degrees of freedom. The wing response and damping (not shown) remain satisfactory; a damping rat lo of the wing vertical bending mode above $30 \%$ critical is achieved even with no flaperon control. The rotor response however 18 unacceptable. The flap response at high gain 1s even larger than open loop. The behavior of the cyclic lag motion, hence the blade loads, 18 simtlar.

It is concluded that a satisfactory controller destgn requires a consideration of the complete dynamic syetem, not just the motion of the wing or the rotor alone. Relaxing the conetraint on part of the syctem allowe only a amell improvement in the response of the rest, which does not coupensate for the deterioration of the dyanic behavior of the unconetrained motions. The optinal control analyole provides a une to design controllers coneidering the entire syoten, both rotor and support, although the resulting designs are by no mans simple.

\section{Kensuremente}

We have found thet the optinal controller is 11 aear otate feedback, wth ajor loope involving alnot all the degrees of freador of the oyotem. As an eltermative to menuring all the degrees of freedom, let w concider the use of a companeation network to estinte the oyoten otates from a lindted nuber

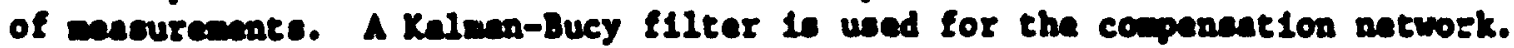
The question is wht menreante are required to catiofectorliy control the

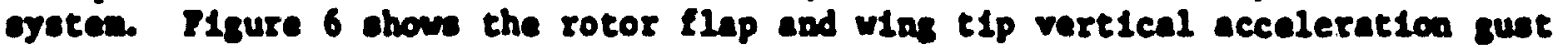



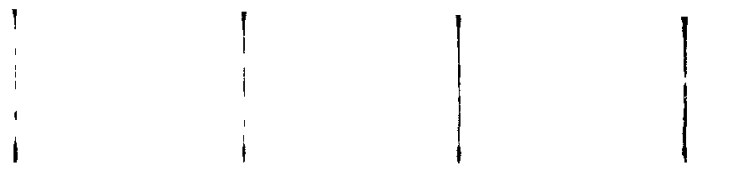

response for various measurements, to be compared with the open loop and opt1mally controlled results of figure 2. Without a measurement of the rotor rotational speed perturbation ( $\psi_{s}$ ), satisfactory control is not generally possible (the closed loop response can be degraded so far as to be larger than open loop even). The japortant role of $\psi_{s}$ in the pruprotor dynamics and control has been pointed out. Since the rotor behaves nearly as if windmilling, an accurate estimate of the rotational spee' perturbations from the motion of the other degrees of freedom is not possible. It 18 necessary to measure $\psi_{\mathrm{g}}$ directly. Figure 6 shows that the flap response remalns high with measurements of the wing motion and the rotor speed perturbation only. It 18 necessary to also measure the rotor flap motion ( $B$, 1.e., gimbal pitch and yaw) to achleve satisfactory control of hoth the wing and rotor motions. Adding measurements of the rotor coning and lag notion $\left(B_{0}, \zeta\right)$, which must be obtained in the rotating frame, does not lmprove the performence much; certainly not enough in view of the great difficulties in obtaining such measurements. The rotor tippath-plane tilt for the gimballed rotor may be measured in the nonrotating frame however.

It 1s observed In f1gure 6 that by measuring the wing motion and the gust velocities, 1.e., the disturbances which dre exciting the system, the gust response may be reduced nearly to the level obtained witin perfect knowledge of the states. (Performance almost this good can be obtalned by measuring only the gust velocities in fact.) Measuring the excitation is therefore a very efficient mean to eatimate the states and thus achieve nearly the optimum controller performance. It is assumel of ccurse that the model of the rotor, support, and gust dynamics used in the Kalman-Bucy filter is an accurate representation of the real system. Errors in the model will degrade the performance.

In sumbary, a compensation network may be used to reduce the measurements required for the proprotor guet alleviation control system. The measurements required for satiafactory control are the wing motion, the rotor rotational speed perturbation, and the rotor t1p-path-plane t1lt. Heasurements in the rotating frame are thus not really required for a glmballed proprotor. An excellent source of Information to the messurement of the exciting gust velocIty Itself, assuning that an accurate wodel is avallable to estinate the states fron the excitation. The compansation network we have used, a KalmanBucy fliter, 1s certainly not eimple of courae. It 18 also noted that the fliter tends to be more seneltive then the deteralaiatic controller to offdeelen operation and to errore in the oyaten model.

\section{Antioymetric Dynutcs}

A enjor difference between the oymatric and antiognetric dyantes of the proprotor alreraft to the effect of the interconnact shaft on the ant1spomatrle notions (refe. 2 axp. 5). The Interconnace shnft Introduces a otrons oprtiss on the rotor az1muth parturbat10n, so the to root becones an oselliatory eode with a frequency above $.5 / \mathrm{rev}$. The spring changes the phace of to relative to the wing extons, with a substantial inpact on the dyande otablilty and gust reoponse (the vins vertical bending oode is atablisied, and 


\begin{tabular}{l|l|l|l|l|l|}
1 & $\vdots$ & 1 & 1 & 1 \\
$i$ & $\vdots$ & 1 & 1
\end{tabular}

the chordwise mode destabilized). The antisymmetric dynamics may be represented with the proprotor and cantilever wing model by simply including the interconnect shaft spring. The open loop gust response for antisymmetric motions is close to that for symmetric motions; the only significant difference is about $25 \%$ lower wing tip vertical acceleration, due to the higher damping of that motion. The 30 response of the wing tip vertical acceleration in CAT is of the order $1.8 \mathrm{~g}$ at max speed. The closed loop (optimal controller) gust response is virtually identical for the symmetric and antisymmerric motions.

The mafor difference between the symmetric and antisymmetric motions is that for the latter the rotor azimuth perturbations result in interconnect shaft and drive train loads, which may be significant. Indeed, for a typical proprotor aircraft, design limit drive train loads are encountered due to antisymmetric longitudinal gusts in cruise mode. Figure 7 shows the gust response of the rctor azimuth perturbation for the case of antisymetric motion and gusts. The open loop response increases to $.3 \mathrm{deg} / \mathrm{m} / \mathrm{sec}$ at maximm speed, which we may consider a measure of the design 11mit loads. The optimal controiler produces a gust response which varies little with speed, and is about $15 \%$ of the uncontrolled level at maximum speed.

\section{Hingeless Rotor}

To examine the influence of the rotor type on the proprotor gust response and control, we also consider a hingeless, soft-coplane proprotor. A complete description of the rotor is given in reference 6 . The rotor has three blades, and a radius of $3.96 \mathrm{~m}$. The flap frequency is approximately $v_{\beta}=1.35 / \mathrm{rev}$ in crilise mode, and the lag frequency $\nu_{\zeta}=.75 / \mathrm{rev}$ (the flap frequency 18 somewhat lower in helicopter mode because of the higher rotor speed). The uncontrolled dynamics of the hingeless proprotor are discussed in reference 6 . There are major differences compared with the open loop dynamics of the gimballed roto:, due to the placement of the natural frequencles of the blade flap and lag motions. It 18 found however that the controlled dynamics and gust response of the gimballed and hingeless rotors are very similar, because for high gain 1t is the feedback loop which determines the system characteristics. A detalled, parallel study of hingeless and gimballed proprotor gust re ponse and alleviation 18 given in reference 14.

Figure 8 shows the rms rotor lag and wing tip vertical acceleration response to gust, for the uncontrolled and optimally controlled system. The flap response 1s similar to the lag response, but smaller; the two blade motions give atout the name blade loads for this rotor, so the lag response 18 critical. The 30 response of the rotor $1 a g$ motion in CAT is of the order $3.2^{\circ}$, which 18 quite high. The rotor response 18 reduced to about $10 \%$ of the open loop value by the optimal controller. The 30 reaponse of the wing t1p vertical acceleration in CAT 1s of the order $1.3 \mathrm{~g}$, which $1 \mathrm{~s}$ reduced to about .28 by the control system. Plgure 8 also shows the gust response uning a Kalman-Bucy filter to estimate the states from varfous measurements. As for the gimballed rotor, it is concluded that it is necesasery to measure the wing wotion, the rotor apeed perturbation, and the rotor tip-path-plane t1lt for adequate performance of the control syotem. Measuremente of the rotor coning 


\section{REFERENCES}

1. Gaffey, T. M., Yen, J. G., and Kvaternik, R. G., "Analysis and Mode1 Tests of the Proprotor Dynamics of a Tilt-Proprotor VTOL Aircraft," U.S. AIr Force V/STOL Technology and Planning Conference, Las Vegas, Nevada, September 1969

2. Anon., "V/STOL Tilt-Rotor Study - Research Aircraft Design," Bell Helicopter Company, NASA CR 114442, June 1972

3. DeTore, J. A., and Sambell, K. W., "Conceptual Design Study of 1985 Commercial Tilt Rotor Transports," NASA CR 2544, November 1974

4. Johnson, Wayne, "Analytical Model for Tilting Proprotor Aircraft Dynamics, Including Blade Torsion and Coupled Kending Modes, and Conversion Mode Operation," NASA TM X-62,369, August 1974

5. Johnson, Wayne, "The Influence of Engine/Transmission/Governor on Tilting Proprotor Alrcraft Dynam1c8," NASA TM X-62,455, June 1975

6. Johnson, Wayne, "Analytical Modeling Requirements for Tilting Proprotor Aircraft Dynamics," NASA TN D-8013, July 1975

7. Bryson, Arthur E., Jr., and Ho, Yu-Ch1, Applied Optimal Control, Blaisdell Publishing Co., Waltham, Massachusett8, 1969

8. Anderson, Brian D. 0. , and Moore, John B., Linear Optimal ntrol, Prentice-Ha11, Inc., Englewood Cliffs, New Jersey, 1971

9. Hall, W. E., Jr., and Bryson, A. E., Jr., "Inclusten of Rotor Dynamics In Controller Design for Helicopter," J. Alrcraft, vol. 10, no. 4, Apr11 1973

10. Gaonkar, Gopal H., and Hohenemser, Kurt H., "Stochastic Properties of Turbulence Excited Totor Blade Vibrations," AIAA Journal, vol. 9, no. 3, . March 1971

11. Gault, J. D., and Gunter, D. E., Jr., "Atmospheric Turbulence Considerat1ons for Future Alrcraft Designed to Operate at Low Altitudes," J. Aircraft, vol. 5, no. 6, November-December 1968

12. Houbolt, John C., Steiner, Roy, and Platt, Kermit G., "Dynamic Response of Airplanes to Atmospheric Turbulence Including Flight Data on Input and Response," MSA TR R-199, June 1964

13. Anon., "Military Specification, Flylng Qualities of Plloted Airplanes," MIL-F-8785B (ASG), U.S. A1r Force, August 1969 


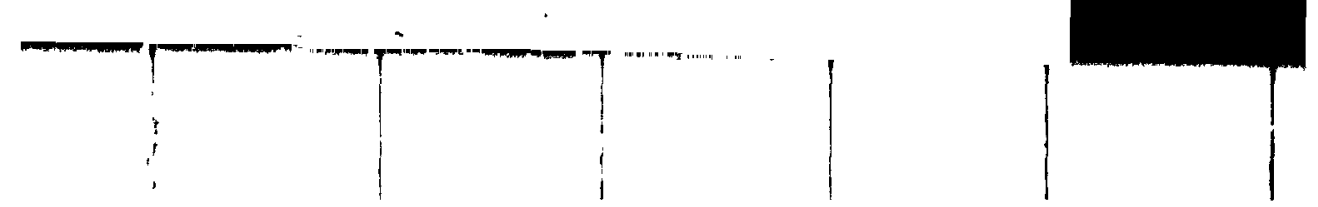

14. Frick, Juanita K., and Johnson, Wayne, "Optimal Control Theory Inves:1gation of Proprotor/Wing Response to Vertical Gust," NASA TM X-62,384, September 1974

15. Anon., "Advancement of Proprotor Technology - Wind-Tunnel Test Results," Be11 Hellcopter Company, NASA CR 114363, September 1971 

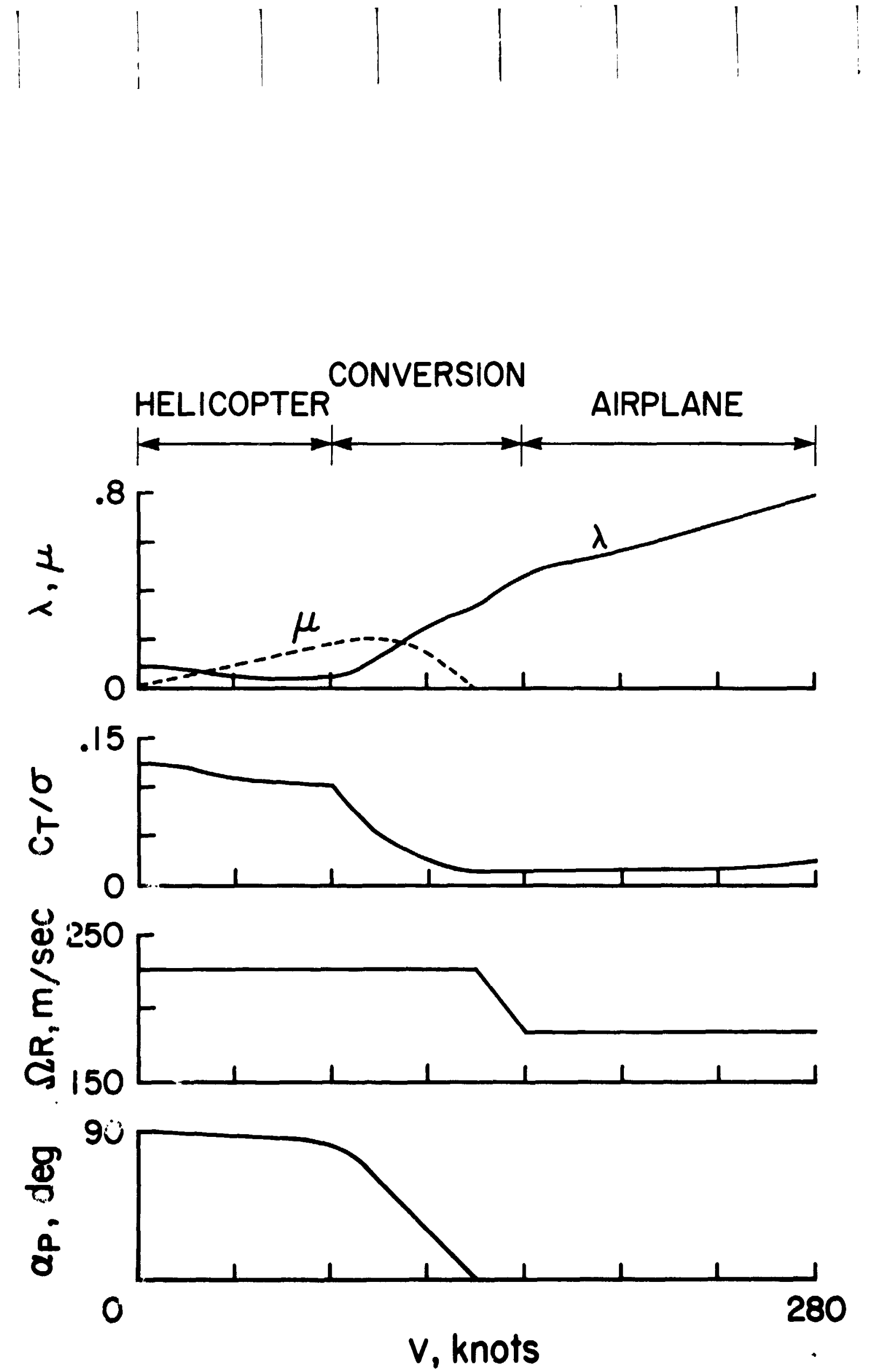

F1gure 1.- G1mballed proprotor operating state: Infloi rat10, advance rat10, thruet, t1p apeed, and pylon angle schedule with forward opeed. 

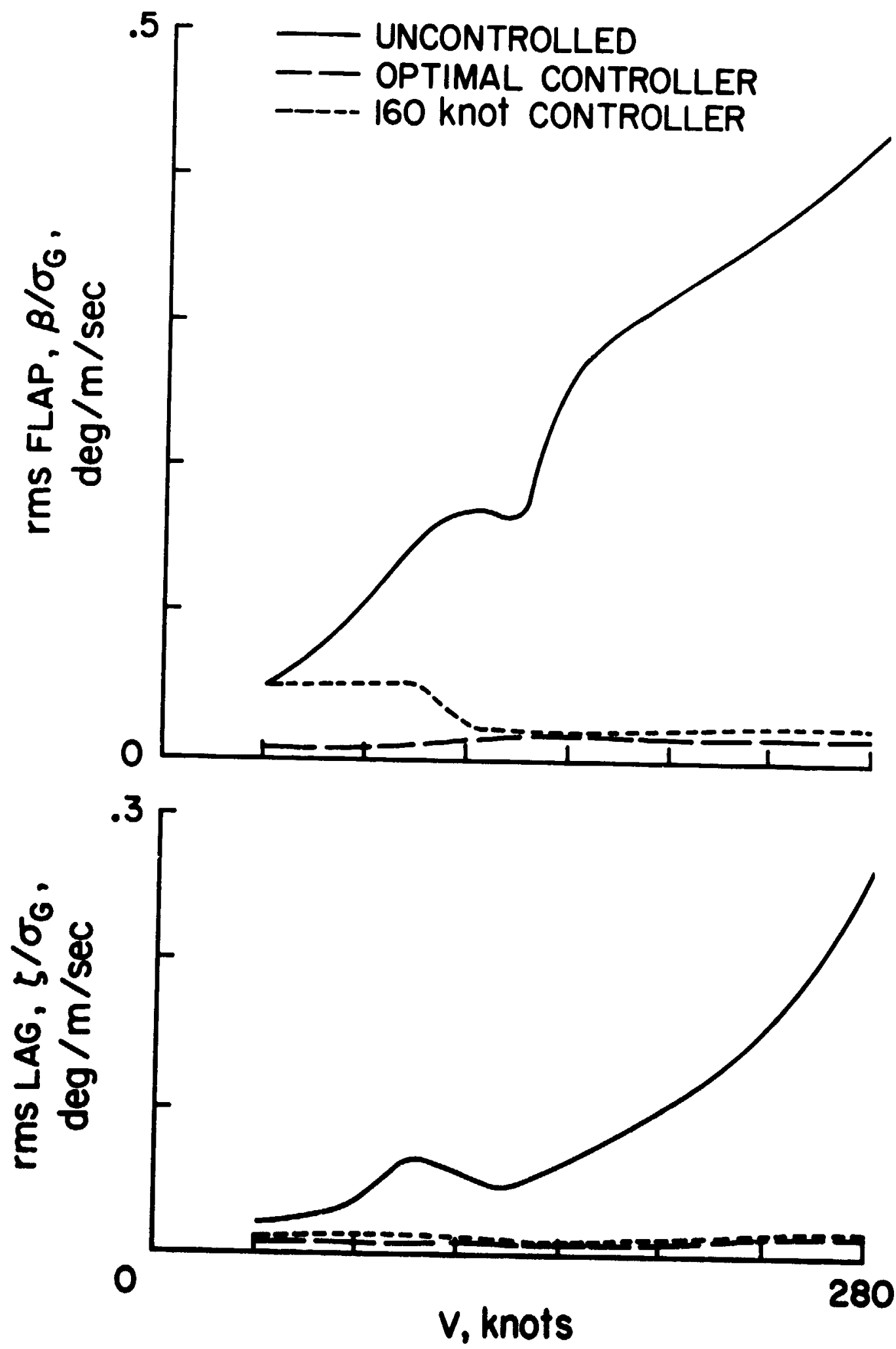

Figure 2.- GL-belled proprotor and wing gust reoponse uncontrolled, whth optinl controller, and wth 160 bnot controller. bo flap and las notion per to guet veloctty, rw wins tip vartical and chordwse eccelexat1on, and ving vertical beading eode daping ratio. 

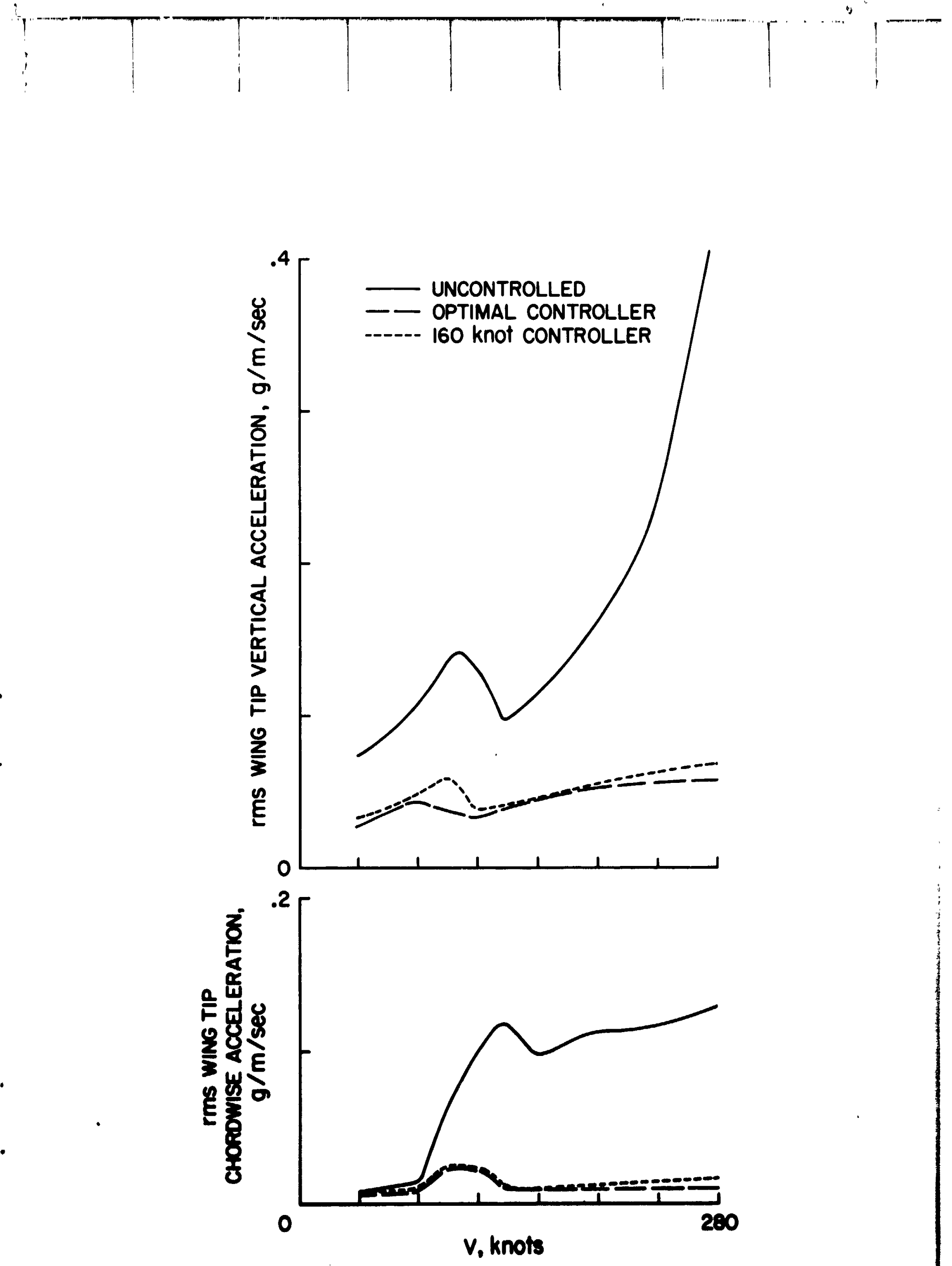

Figure 2.- Continued. 


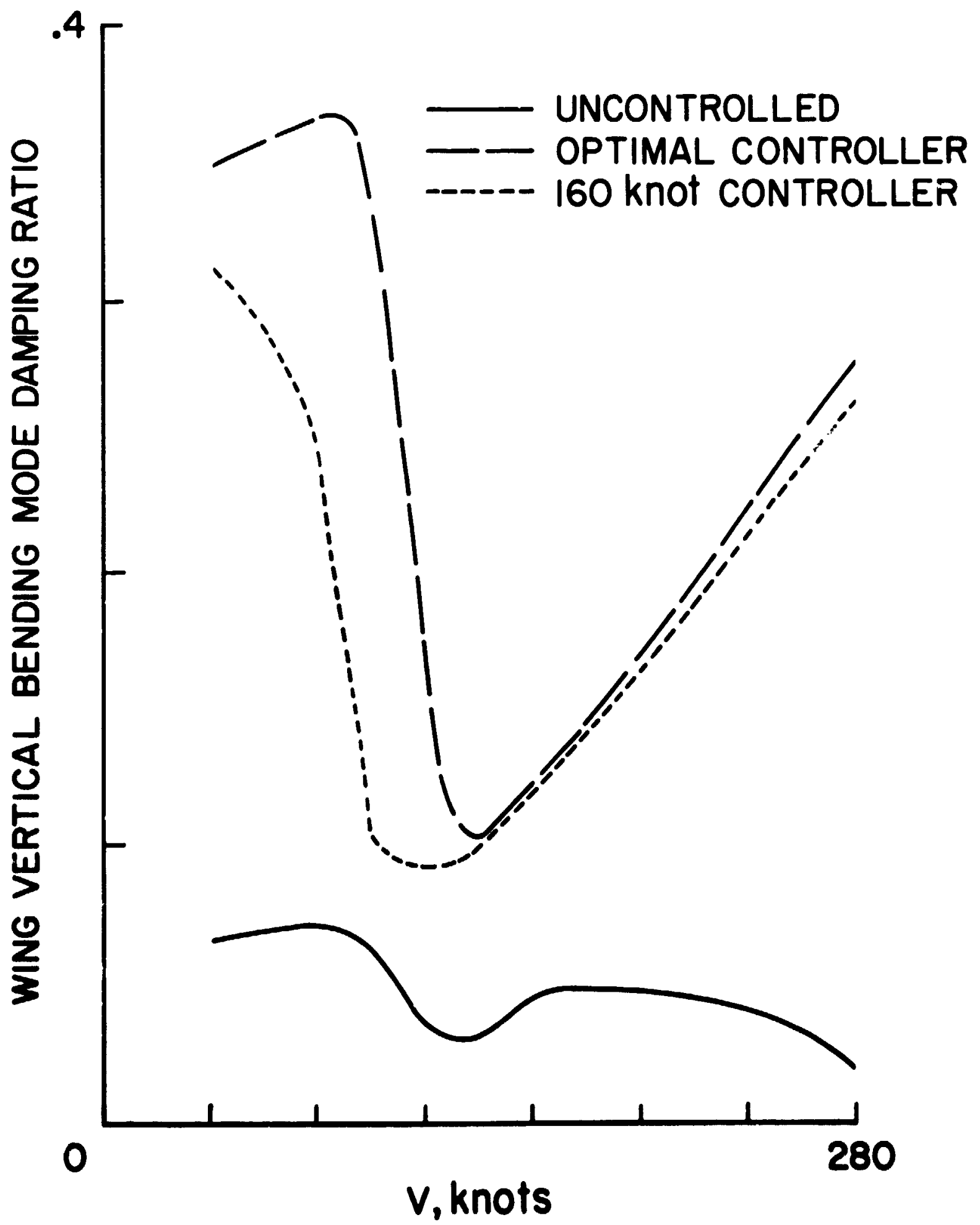

I1gure 2.- Concluded. 

OPTIMAL CONTROLLER

- - WITHOUT WING FLAPERON CONTROL ROTOR CONSTRAINT ONLY 


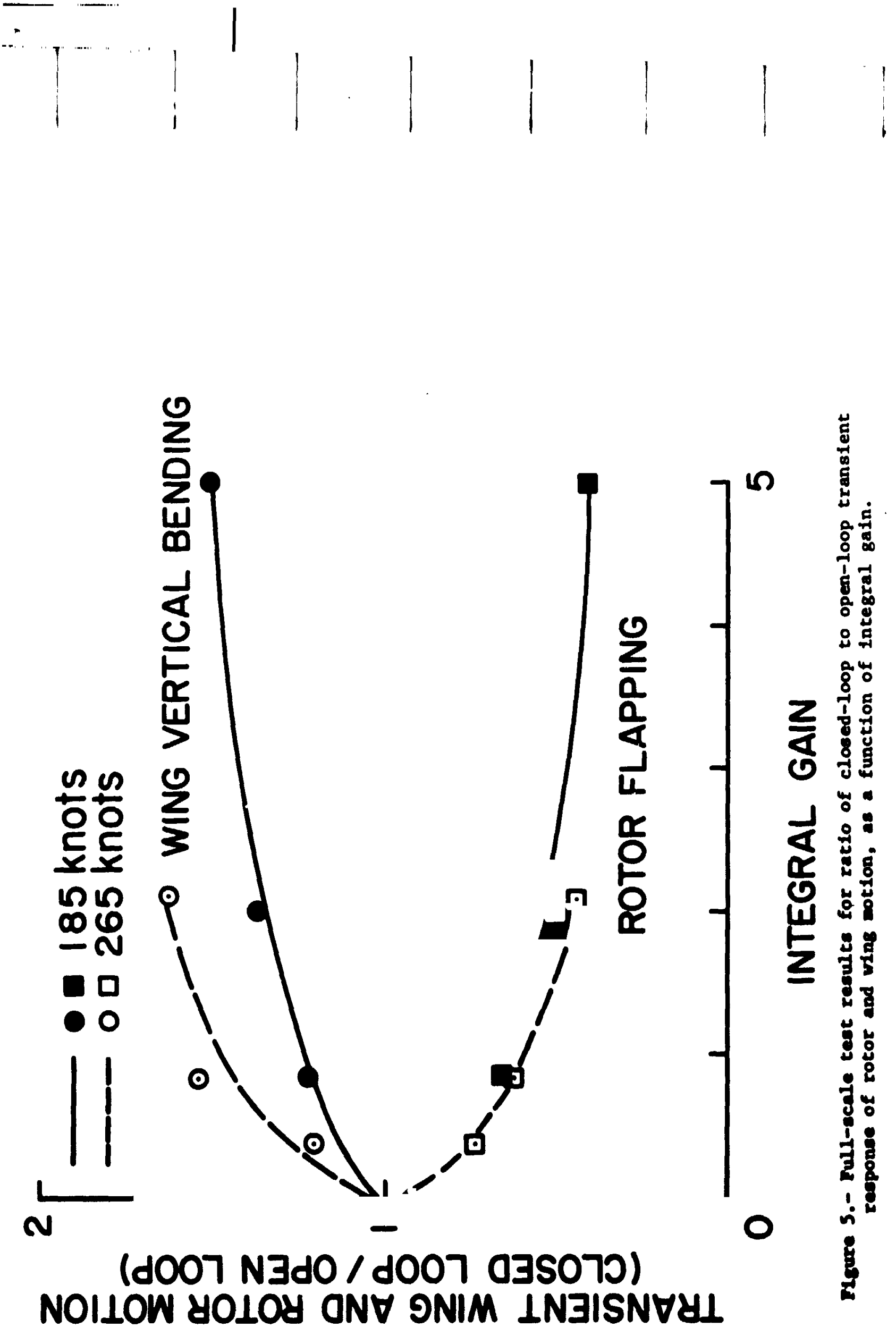


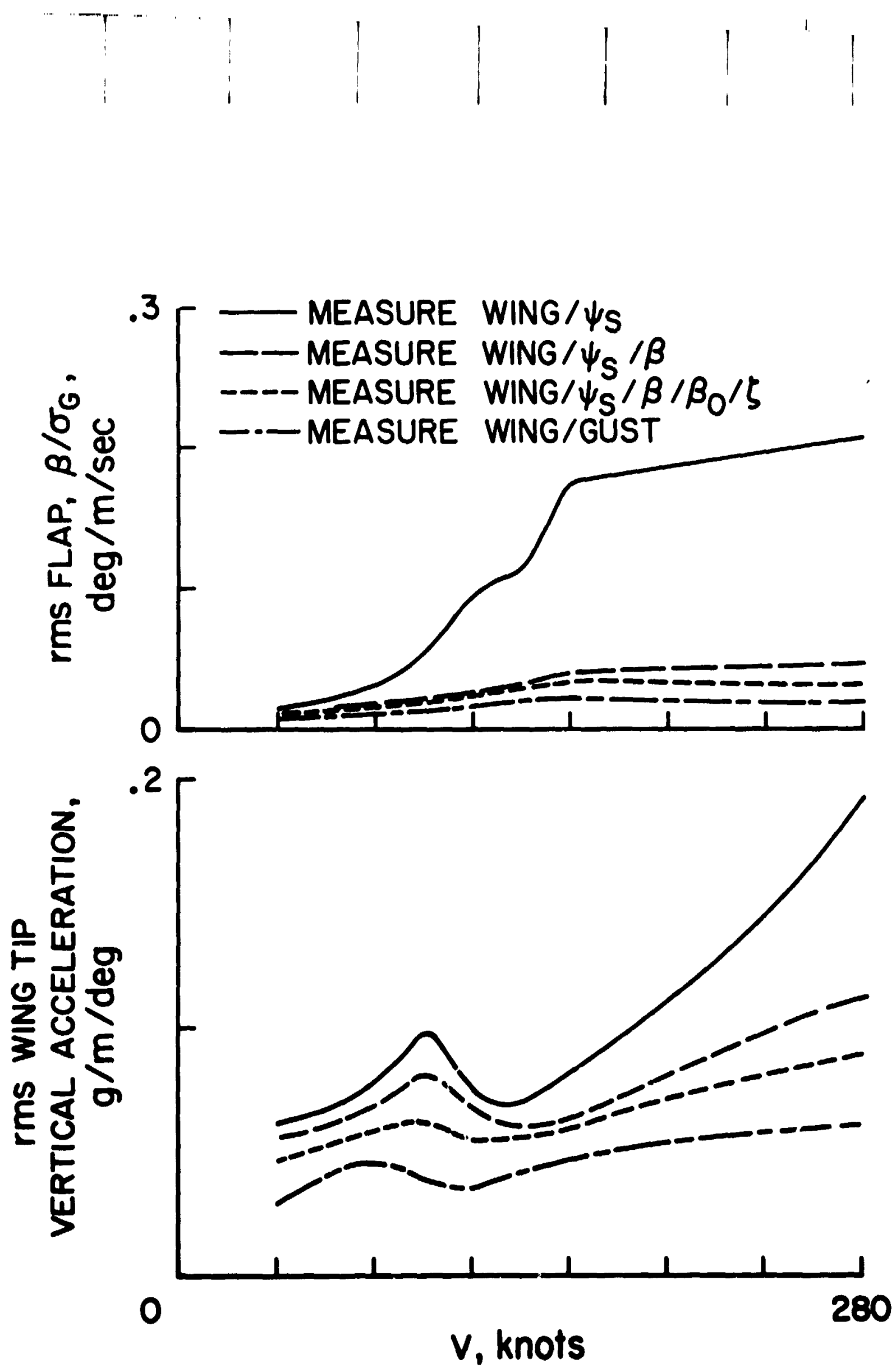

T1gure 6.- Lotor tlap and whe tip vertical scceleretion gust reaponse for

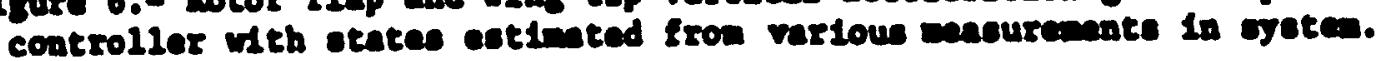




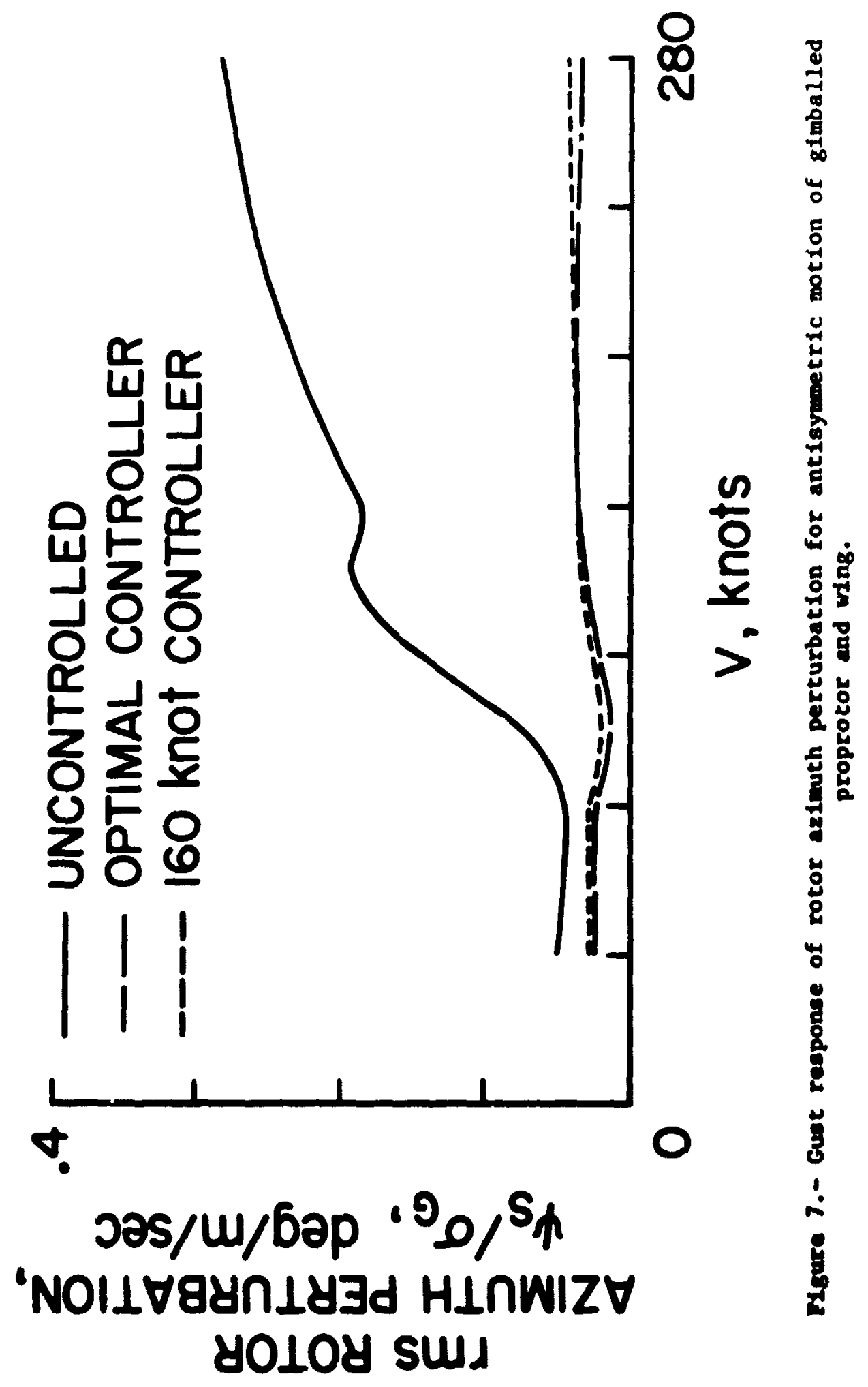


$\begin{array}{lll}1 & 1 \\ 1 & 1 & 1\end{array} \mid$
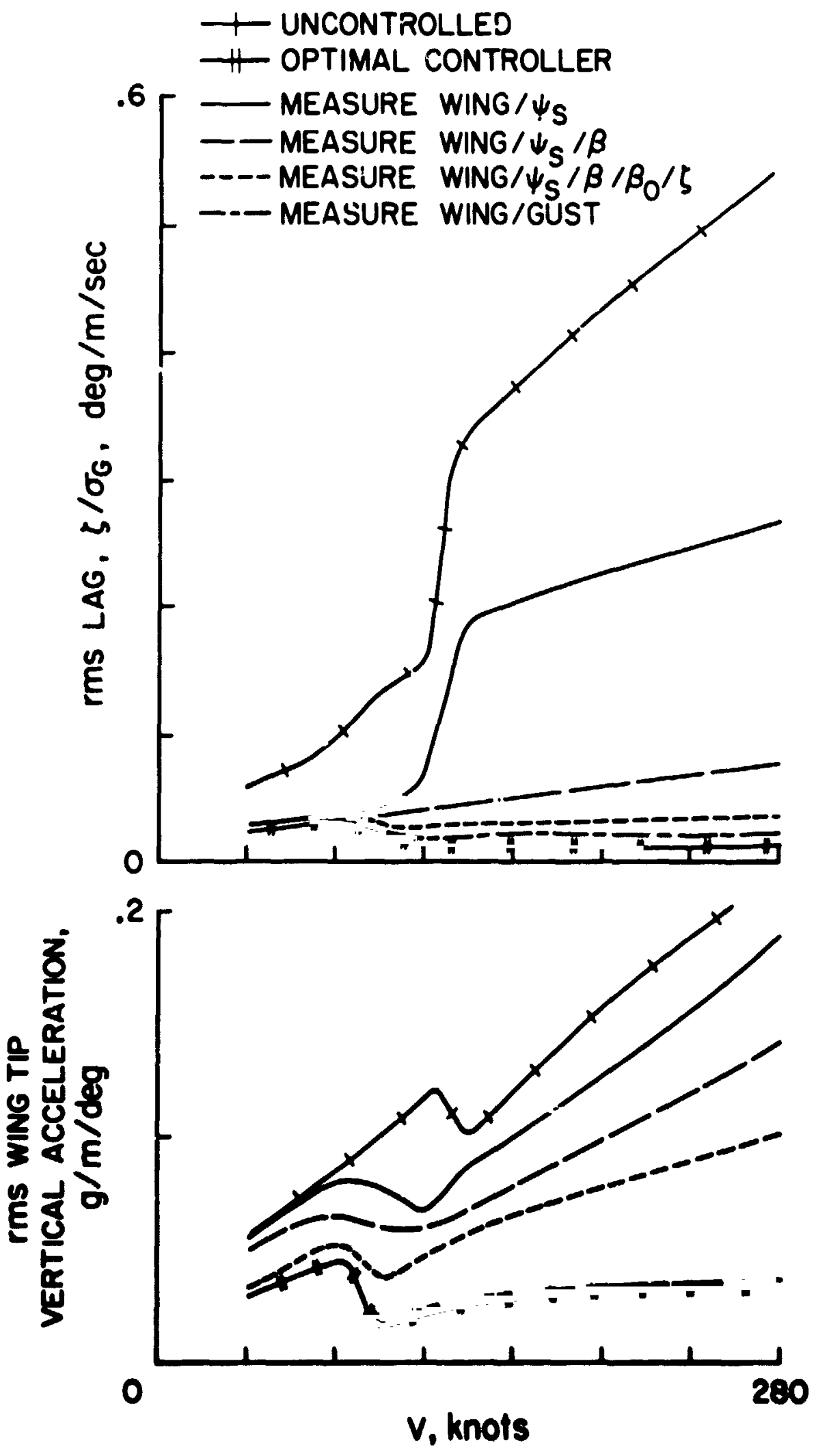

Troure 8. - Alaceleas proprotor and vins sust repponse (zotor In wetioc and wins tip vertical ecenleration) uncentrolled,

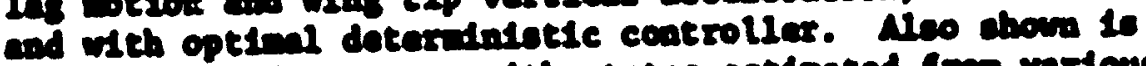
che controllad reoposise whth states cotinated from vartous esacurrensates. 